\title{
elsevier_VETMIC_6859
}

\section{Genetic diversity of the VP7, VP4 and VP6 genes of Korean porcine group C rotaviruses}

Young-Ju Jeong a

Jelle Matthijnssens ${ }^{\mathrm{b}, \mathrm{F} \text {, }}$

jelle.matthijnssens@uz.kuleuven.ac.be

Deok-Song Kim ${ }^{a}$

Ji-Yun Kim ${ }^{a}$

Mia Madel Alfajaroa

Jun-Gyu Parka

Myra Hosmilloa

Kyu-Yeol Son ${ }^{\mathrm{a}}$

Mahmoud Soliman ${ }^{a}$

Yeong-Bin Baek ${ }^{a}$

Joseph Kwon ${ }^{\circ}$

Jong-Soon Choi

Mun-II Kang ${ }^{a}$

Kyoung-Oh Cho $0^{\mathrm{a}}$ *

choko@chonnam.ac.kr

aLaboratory of Veterinary Pathology, College of Veterinary Medicine, Chonnam National University, Gwangju, Republic of Korea

${ }^{\mathrm{b}} \mathrm{KU}$ Leuven = University of Leuven, Department of Microbiology and Immunology, Laboratory for Clinical and Epidemiological Virology, Rega Institute for Medical Research, B-3000 Leuven, Belgium

'Division of Life Science, Korea Basic Science Institute, 169-148 Gwahak-ro, Yuseong-gu, Daejeon 305-806, Republic of Korea

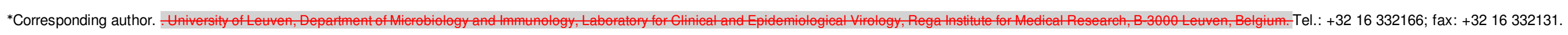

${ }^{* *}$ Corresponding authortaboratory of Veterinary Pathology, College of Veterinary Medieine, Chonnam National University, Gwangju, Republie of Korea. Tel.: +82 $625302845 ;$ fax: +82 625300835.

\section{Abstract}

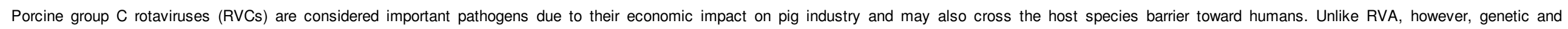

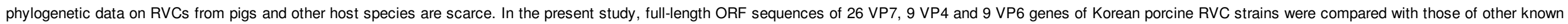

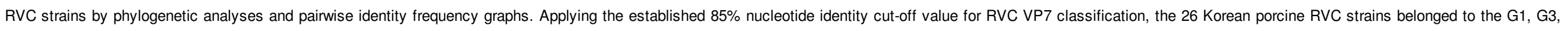

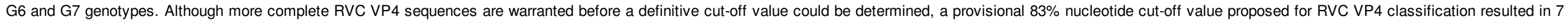

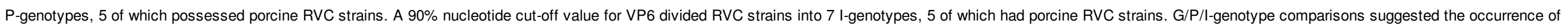

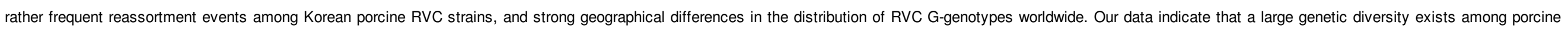


Keywords: Porcine; Group C rotavirus; VP7; VP4; VP6; Genetic diversity

\section{Introduction}

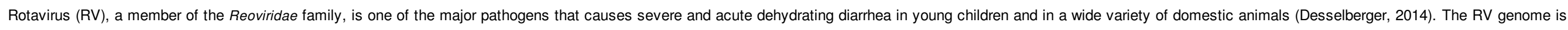

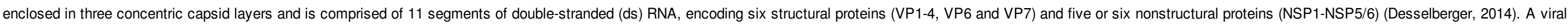

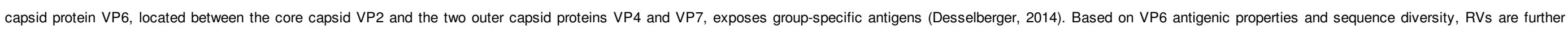
classified into 7 groups (RVA-RVG) (Desselberger, 2014). Recently, the human RV strains NADRV-J19, ADRV-N and NADRV-B219 were tentatively assigned to a novel RV species H (RVH) (Matthijnssens et al., 2012).

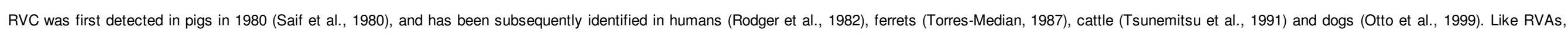

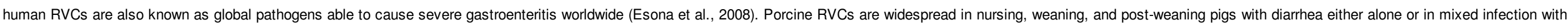

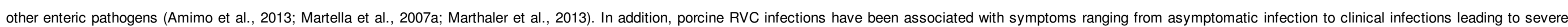

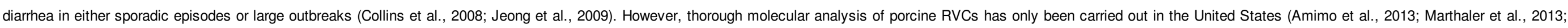
Tsunemitsu et al., 1996), Italy (Martella et al., 2007ab,b), Ireland (Collins et al., 2008), South Korea (Jeong et al., 2009), Canada (Marthaler et al., 2013), and the Czech Republic (Mouteliková et al., 2014).

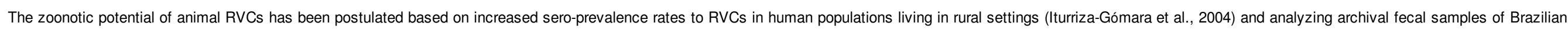

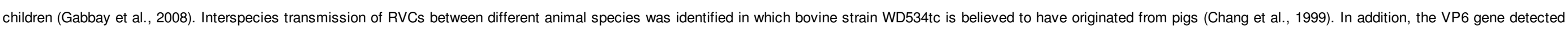
in the piglet belonged to the bovine RVC lineage, indicating possible interspecies transmission or genetic reassortment of RVC between bovine and porcine RVCs (Jeong et al., 2009).

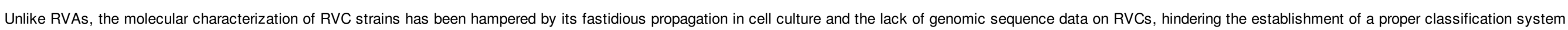

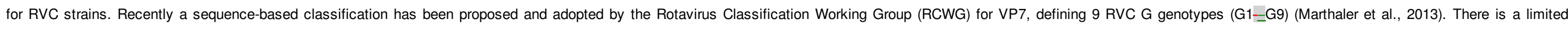
number of RVC VP4 and VP6 sequences available, but no official RVC VP4 (P-genotypes) or VP6 (I-genotypes) classification has been proposed (Mawatari et al., 2014; Moutelíková et al., 2014).

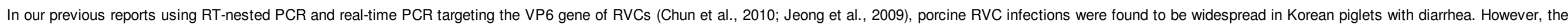

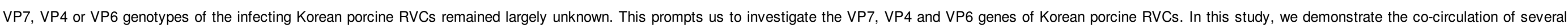

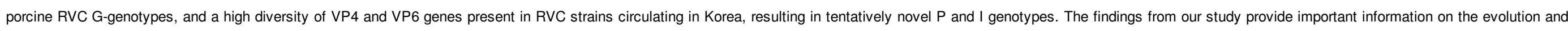
genetic diversity of circulating RVC strains.

\section{Materials and methods}

\subsection{Specimens}

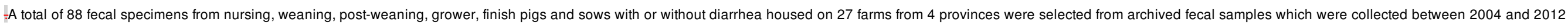

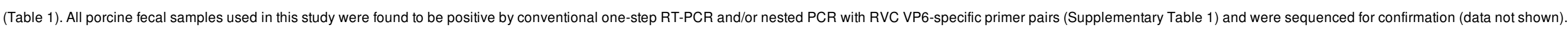

Table 1 Information of fecal samples from which full-length ORF sequences of VP7, VP4 and VP6 genes of RVCs were obtained.

\begin{tabular}{|c|c|c|c|c|c|c|c|}
\hline \multirow[t]{2}{*}{ Fecal Anno. } & \multirow[t]{2}{*}{ County ${ }^{\mathrm{a}}$} & \multirow[t]{2}{*}{ Year of collection } & \multirow[t]{2}{*}{$\mathrm{Age}^{\mathrm{b}}$} & \multirow[t]{2}{*}{ Diarrhea status ${ }^{c}$} & \multicolumn{3}{|c|}{ Genotypes $^{d}$} \\
\hline & & & & & $G$ & $P$ & I \\
\hline $04-155-1$ & $G$ & 2004 & 42 & D & 3 & & \\
\hline $04-155-5$ & $G$ & 2004 & 60 & D & 1 & & 7 \\
\hline
\end{tabular}




\section{elsevier_VETMIC_6859}

\begin{tabular}{|c|c|c|c|c|c|c|c|}
\hline 04-97-1 & 1 & 2004 & 60 & $D$ & 7 & & \\
\hline $04-105-2$ & Go & 2004 & 56 & D & & & 7 \\
\hline $06-52-1$ & M & 2006 & 35 & D & & & 6 \\
\hline $06-52-2$ & $M$ & 2006 & 150 & D & 7 & & \\
\hline 06-69-1 & $M$ & 2006 & 30 & D & 7 & & \\
\hline $06-92-1$ & $Y$ & 2006 & 6 & D & & & 5 \\
\hline $06-144-2$ & $S$ & 2006 & 70 & D & 3 & 1 & 7 \\
\hline $06-176-1$ & C & 2006 & 42 & D & 6 & & \\
\hline 06-238-2 & $Y$ & 2006 & 35 & D & 1 & & \\
\hline 06-268-2 & $\mathrm{J}$ & 2006 & 63 & D & & 5 & \\
\hline $06-281-4$ & M & 2006 & 15 & D & 6 & & \\
\hline $07-60-4$ & $\mathrm{Gi}$ & 2007 & 80 & D & 6 & 5 & \\
\hline $07-74-11$ & $M$ & 2007 & 35 & D & 1 & 7 & 4 \\
\hline 07-109-12 & $S$ & 2007 & 6 & D & 6 & 4 & \\
\hline $08-128-1$ & C & 2008 & 5 & D & 7 & & 4 \\
\hline $08-148-2$ & Go & 2008 & 3 & D & & 7 & \\
\hline $09-15-7$ & Ye & 2009 & 7 & D & 6 & & 4 \\
\hline $09-15-9$ & Ye & 2009 & 8 & D & 3 & & 4 \\
\hline $09-43-8$ & $Y$ & 2009 & 5 & D & 3 & & \\
\hline $09-47$ & D & 2009 & 21 & D & 3 & & \\
\hline $09-84-5$ & Ys & 2009 & 21 & D & 7 & & \\
\hline $11-58-4$ & $Y$ & 2011 & Sow & ND & 7 & & \\
\hline $11-58-7$ & $Y$ & 2011 & Sow & ND & 7 & & \\
\hline 2885 & Y & 2012 & 22 & ND & 7 & 6 & \\
\hline 1027 & Y & 2012 & 19 & D & 7 & 6 & \\
\hline 2846 & Go & 2012 & 25 & ND & 3 & & \\
\hline 2455 & Go & 2012 & 25 & ND & 3 & & \\
\hline $50-12$ & Go & 2012 & 30 & D & 3 & & \\
\hline $61-12$ & $Y$ & 2012 & 21 & ND & 6 & & \\
\hline 2478 & $Y$ & 2012 & 55 & $D$ & & 7 & \\
\hline
\end{tabular}

a G: Gwangyang, I: Iksan, Go: Gochang, M: Muan, S: Shinan, C: Chonan, Y: Yeonggwang, J: Jeongeup, Gi: Gimje, S: Suncheon, Ye: Yeongam, D: Damyang, and Ys: Yesan counties_

${ }^{b}$ The age is in days.

${ }^{\mathrm{c}} \mathrm{D}$ : Diarrhea, ND: none diarrheal. 


\section{elsevier_VETMIC_6859}

d Genotypes: Genotypes of VP7, VP4 and VP6 identified in this study are written for each sample.

\subsection{RNA extraction}

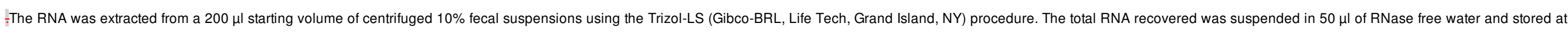
$-80^{\circ} \mathrm{C}$ until further use.

\subsection{RT-PCR}

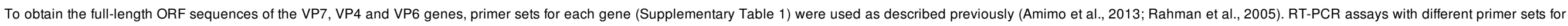

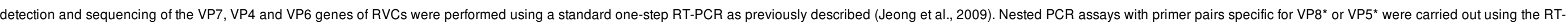
PCR products (Jeong et al., 2009). The RT-PCR and nested PCR products were analyzed by 1 or $1.5 \%$ agarose gel electrophoresis and visualized by UV after ethidium bromide staining

\subsection{DNA sequencing}

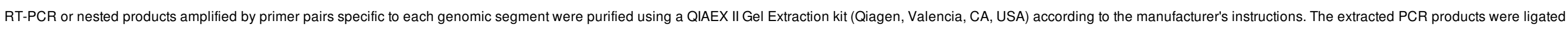

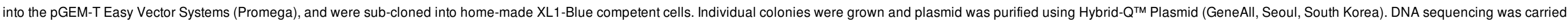
out using an ABI System 3700 automated DNA sequencer (Applied Biosystems, Foster City, CA, USA)

\subsection{Genebank accession numbers}

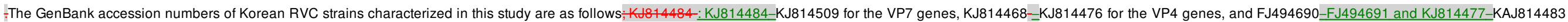
for the VP6 genes. Details of Korean and other known strains are shown in Supplementary Table 2.

\subsection{Phylogenetic analysis}

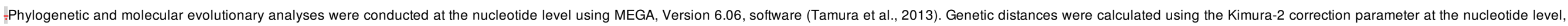
and trees were constructed using the Neighbor joining algorithm.

\subsection{Construction of pairwise identity graphs}

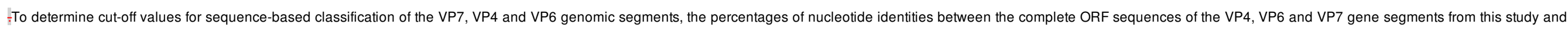

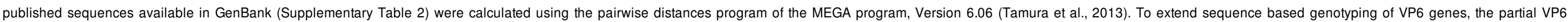

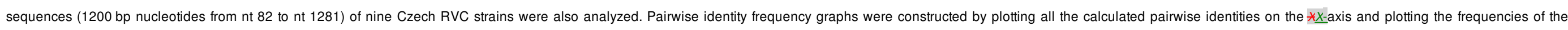
calculated pairwise identities on the $¥ \underline{y}$-axis (Ball, 2005).

\section{Results}

\subsection{Sequence and phylogenetic analyses of the VP7 genes of Korean RVC strains}

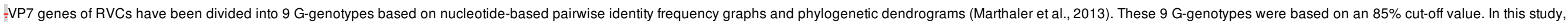

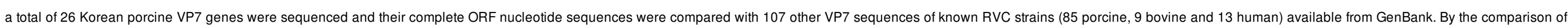

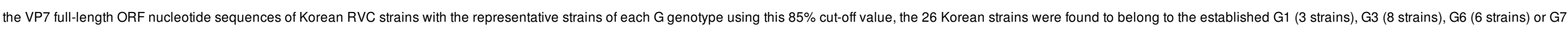

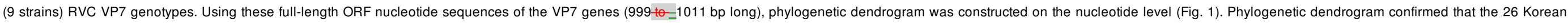
porcine RVC strains were classified appropriately to the G1, G3, G6 and G7 genotypes, suggesting a large genetic diversity of porcine RVC strains circulating in Korea (Fig. 1).

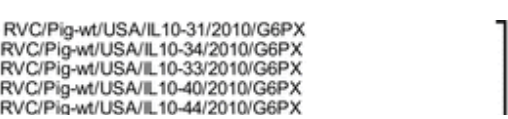




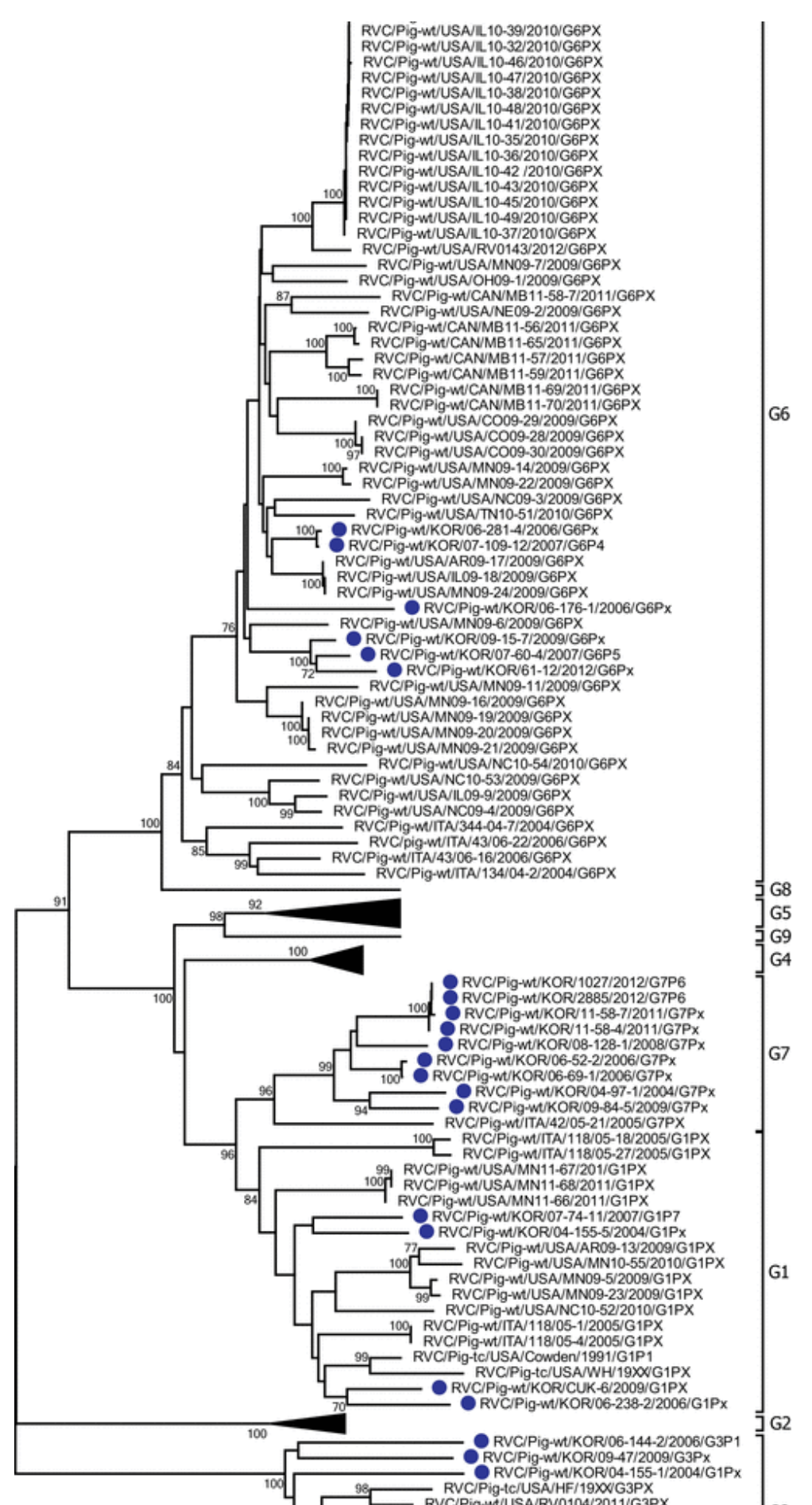

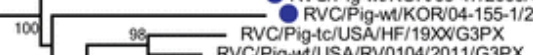


number of sequences, and the width represents the genetic diversity inside that cluster. Korean porcine strains obtained in this study are indicated with a filled circle.

\subsection{Sequence and phylogenetic analyses of the VP4 genes of Korean RVC strains}

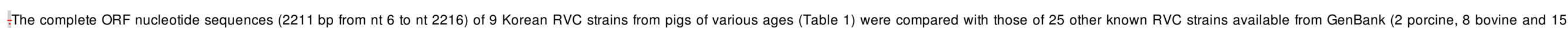

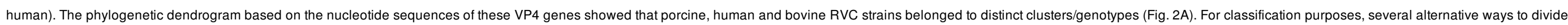

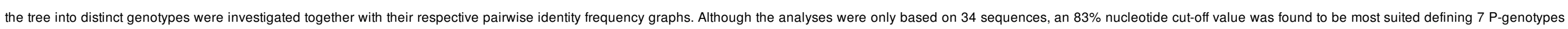

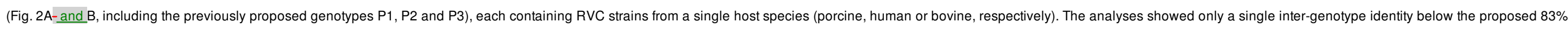

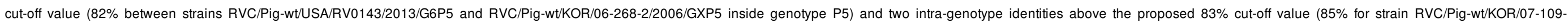

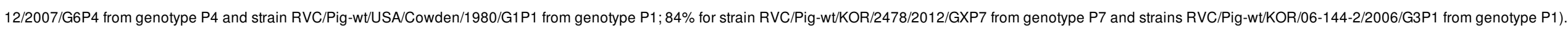


A.

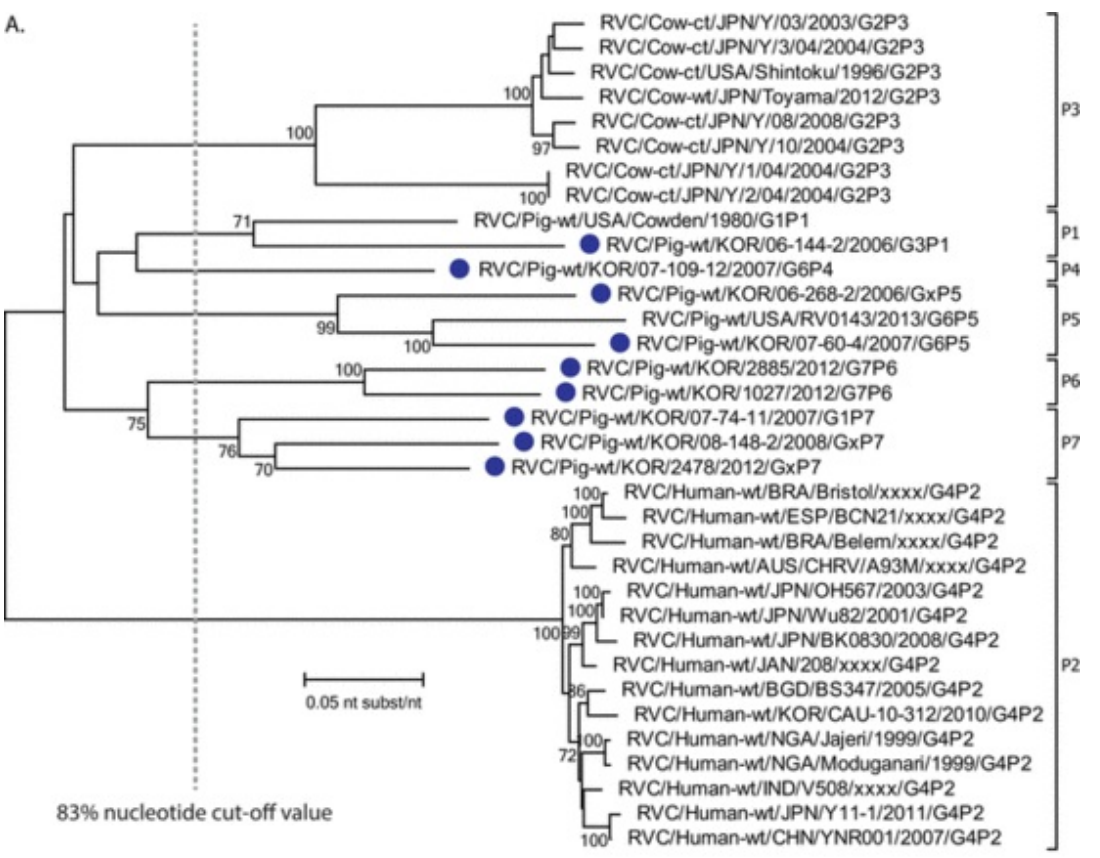

B.

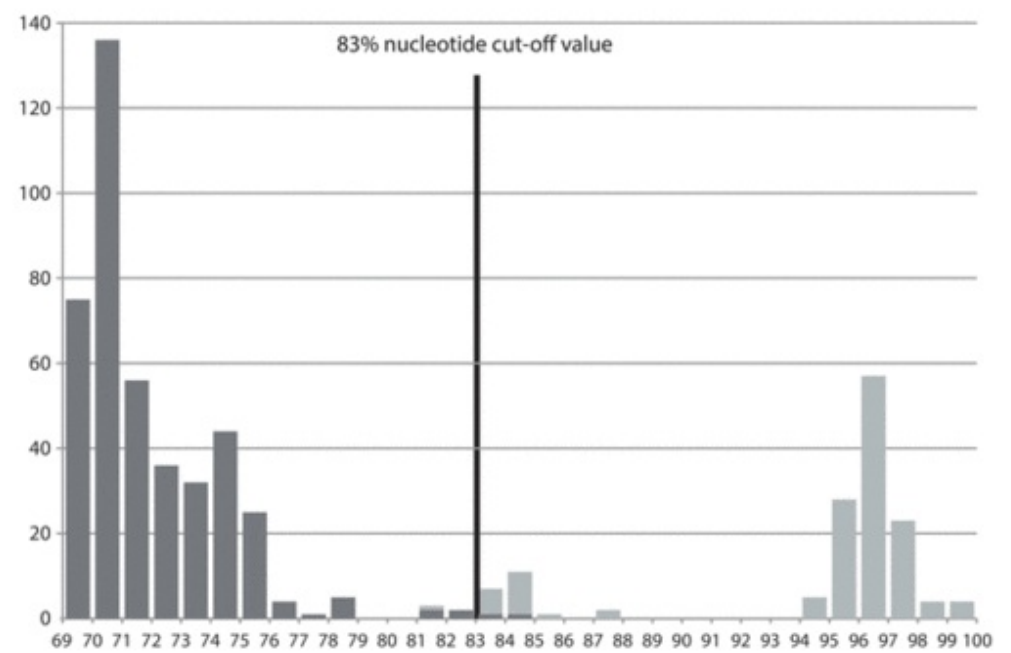

Inter genotype identities

IIntra genotype identities

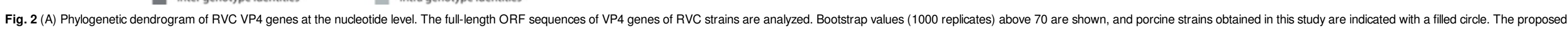

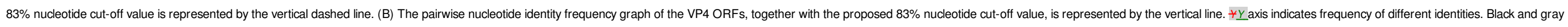
bars indicate inter-genotype and intra-genotype identities, respectively.

\subsection{Sequence and phylogenetic analyses of the VP6 genes of Korean RVC strains}

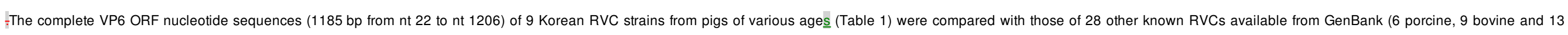




\section{elsevier_VETMIC_6859}

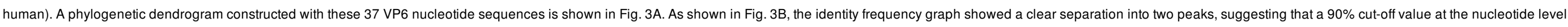

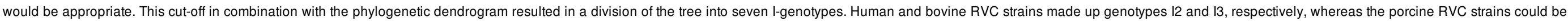
further divided into 5 I genotypes: 11 and 14-17 (Fig. 3A).
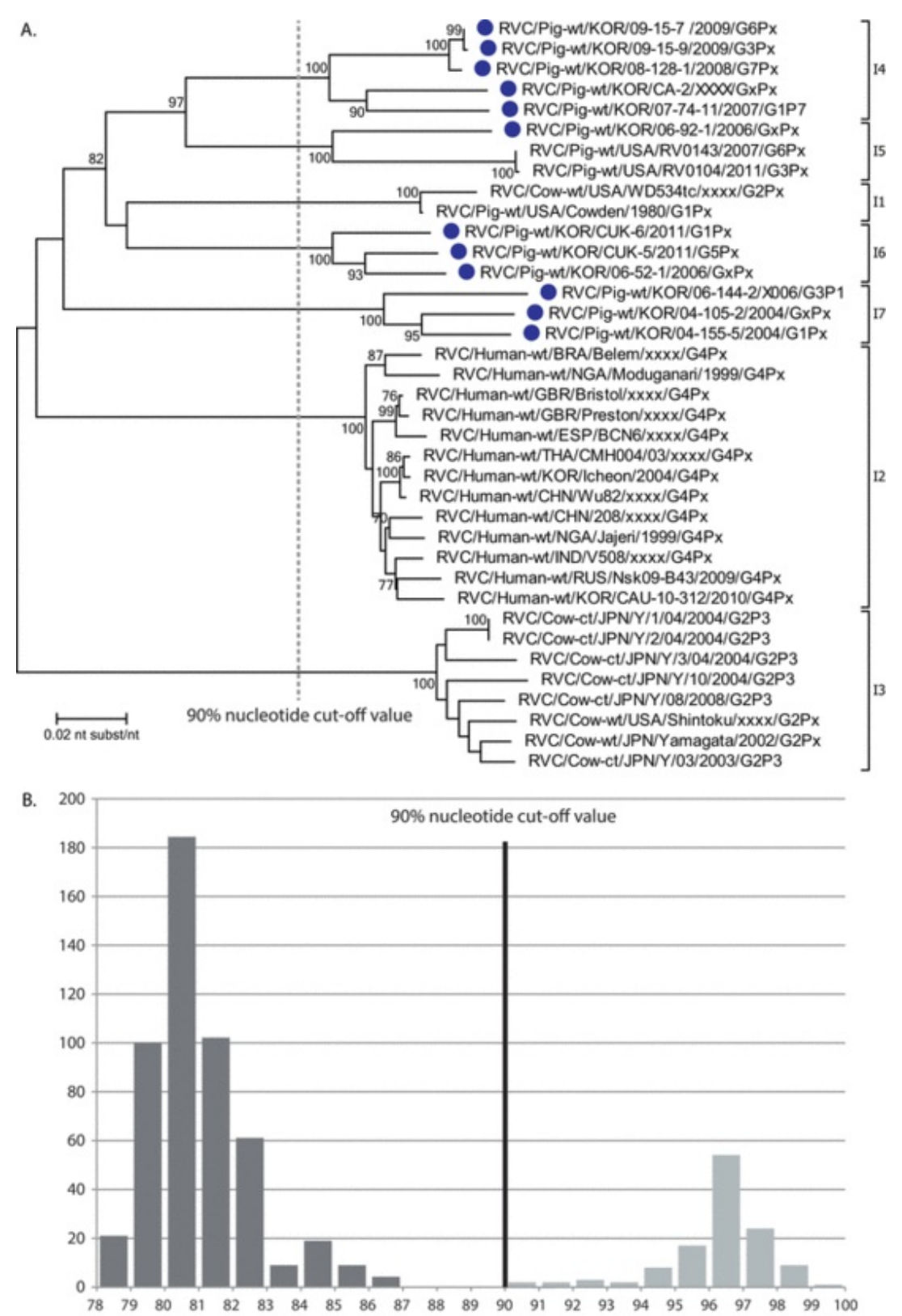
Inter genotype identities
Intra genotype identities

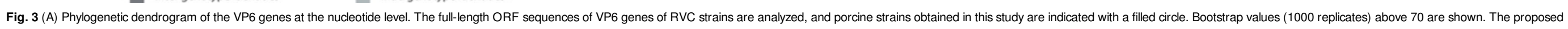




\section{elsevier_VETMIC_6859}

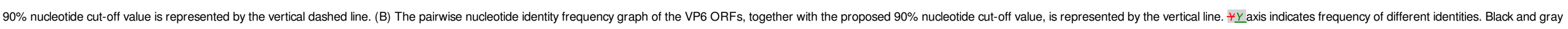
bars indicate inter-genotype and intra-genotype identities, respectively.

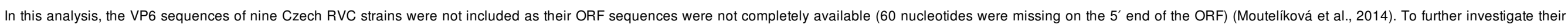

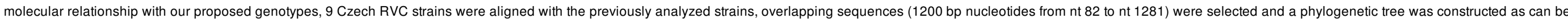

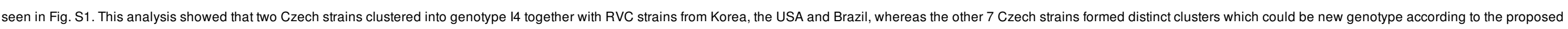
$90 \%$ cut-off value (data not shown). However, their nucleotide sequences should be completed before they can be ratified as new genotypes.

\subsection{Reassortment events}

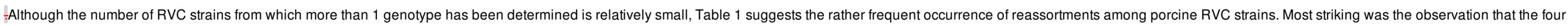

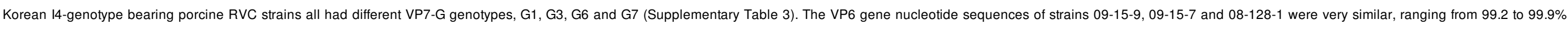

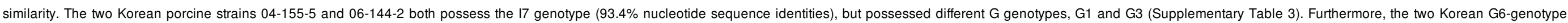

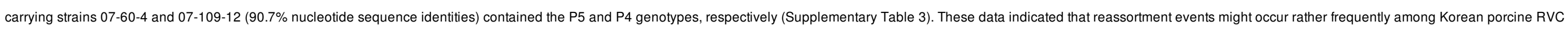
strains.

\section{Discussion}

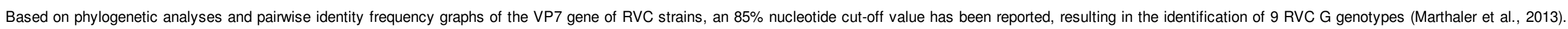

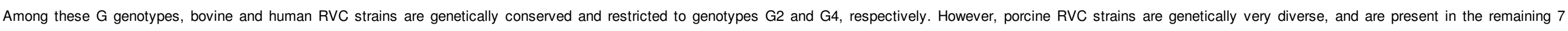

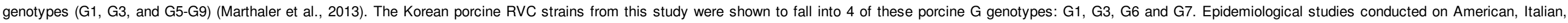

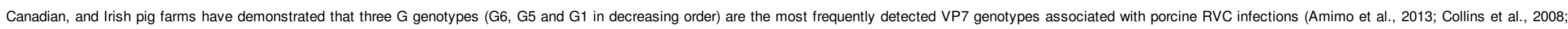

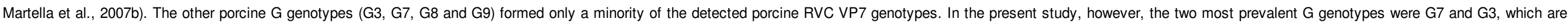

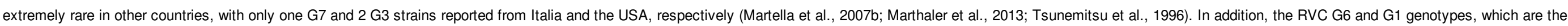

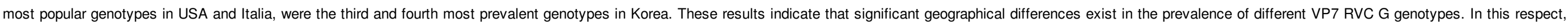
further longitudinal surveillance studies will be crucial to investigate the dynamics of different RVC G-genotypes, and to see if strong genotype fluctuation can occur from one year to the next as is known for RVA.

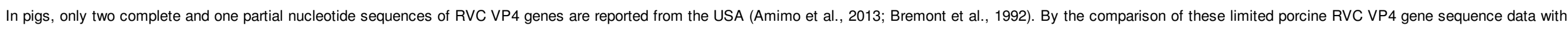

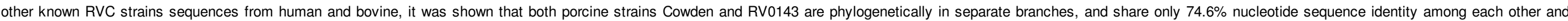

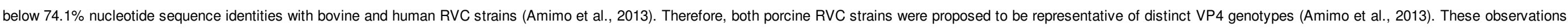

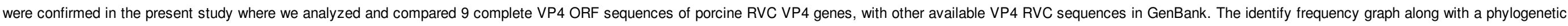

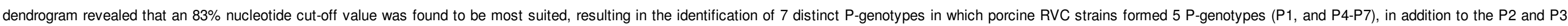

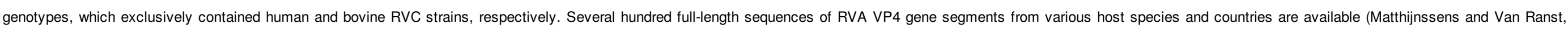

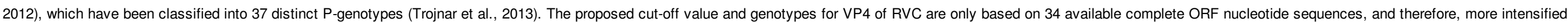
epidemiological studies throughout the world will need to be conducted in order to determine if the currently proposed $83 \%$ cut-off value is the most suited for RVC VP4 classification into P-genotypes.

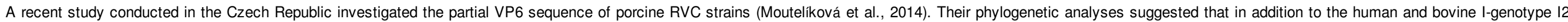

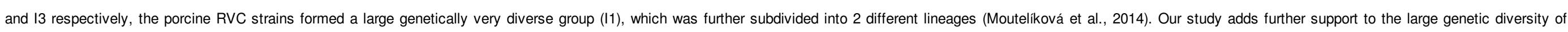

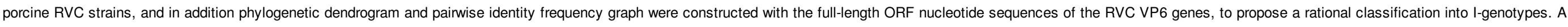

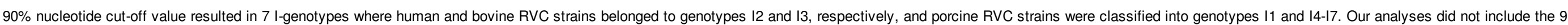

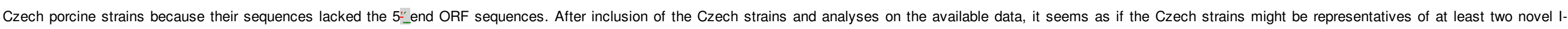

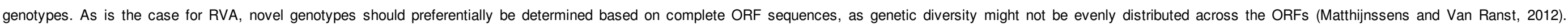
Therefore, these potentially novel genotypes were not yet assigned an l-genotype number, until the complete ORF has been analyzed. 


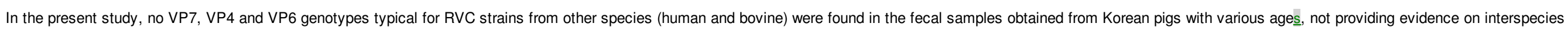

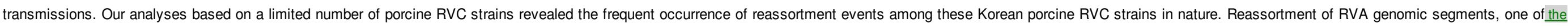

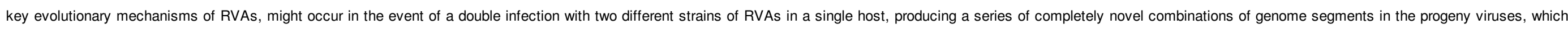

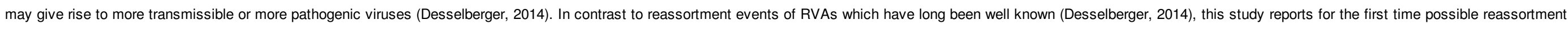

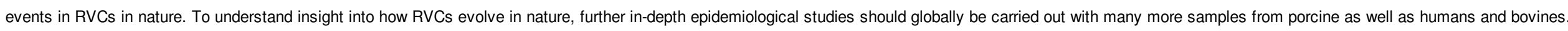

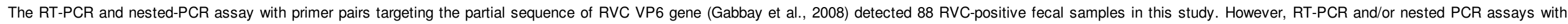

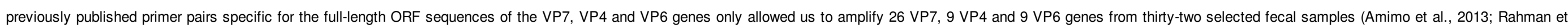

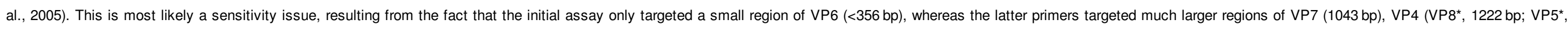
$1179 \mathrm{bp})$ and VP6 (1352 bp) genes of RVC.

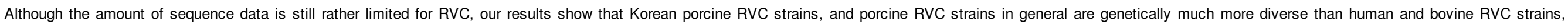
suggesting that pigs are the main reservoir for RVC strains. Further epidemiological studies are likely to reveal the presence of additional genotypes in humans and animals worldwide.

\section{Acknowledgments}

This study was supported by the Korea Basic Science Institute grant (G33730C33730) and Chonnam National University (2013).

\section{Appendix A. Supplementary data}

Supplementary data associated with this article can be found, in the online version, at http://dx.doi.org/10.1016/j.vetmic.2014.12.024.

\section{References}

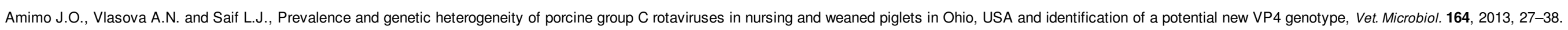

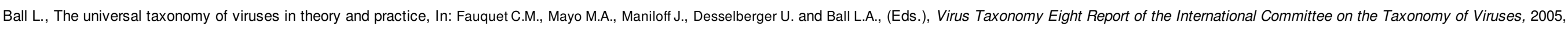
Elsevier; Amsterdam, The Netherlands, 3-8.

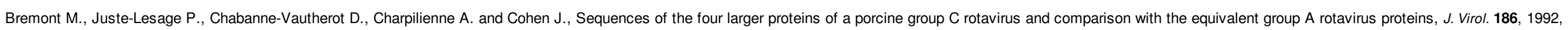
684-692.

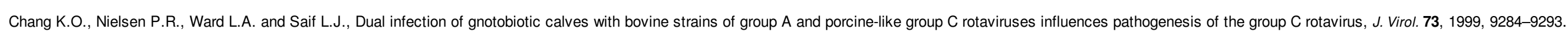

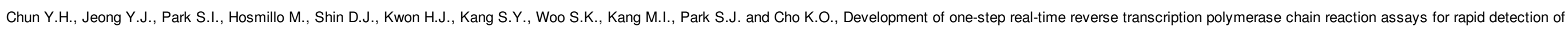
porcine group C rotaviruses, J. Vet. Diagn. Investiq. 22, 2010, 74-77.

Collins P.J., Martella V. and O'Shea H., Detection and characterization of group C rotaviruses in asymptomatic piglets in Ireland, J. Clin. Microbiol. 46, 2008, 2973-2978.

Desselberger U., Rotaviruses. Rotaviruses, Virus Res. 190, 2014, 75-96.

Esona M.D., Humphrey C.D., Dennehy P.H. and Jiang B., Prevalence of group C rotavirus among children in Rhode Island, United States, J. Clin. Virol. 42, 2008, 221-224.

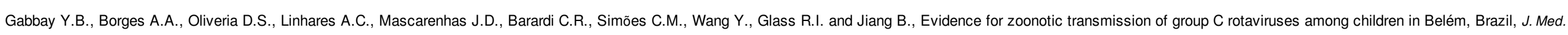
Virol. 80, 2008, 1666-1674.

Iturriza-Gómara M., Clarke I., Desselberger U., Brown D., Thomas D. and Gray J., Seroepidemiology of group C rotavirus infection in England and Wales, Eur. J. Epidemifol. 19, $2004,589-595$.

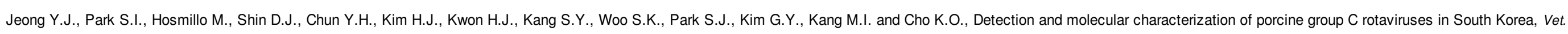




\section{elsevier_VETMIC_6859}

Microbiol. 138, 2009, 217-224.

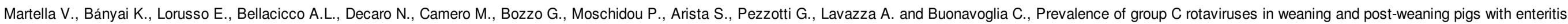
Vet. Microbiol_ 123, 2007a, 26-33.

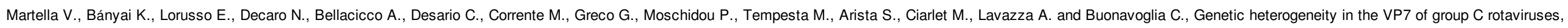
Virology 367, 2007b, 358-366.

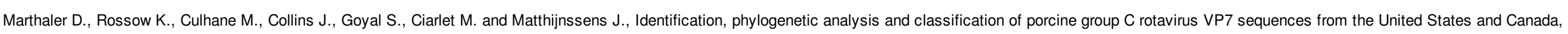

Virology 446, 2013, 189-198.

Matthijnssens J., Otto P.H., Ciarlet M., Desselberger U., Van Ranst M. and Johne R., VP6-sequence-based cutoff values as a criterion for rotavirus species demarcation, Arch. Virol_ 157, 2012, 1177-1182.

Matthijnssens J. and Van Ranst M., Genotype constellation and evolution of group A rotaviruses infecting humans, Curr. Opin. Virol. 2, 2012, 426-433.

Mawatari T., Hirano K., Tsunemitsu H. and Suzuki T., Whole-genome analysis of bovine rotavirus species C isolates obtained in Yamagata, Japan, 2003--2010, J. Gen. Virol. 95, 2014, 1117-1125.

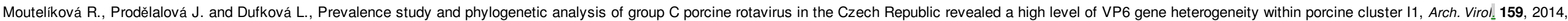
$1163-1167$.

Otto P., Schulze P. and Herbst W., Demonstration of group C rotaviruses in fecal samples of diarrheic dogs in Germany, Arch. Virol. 144, 1999, 2467-2473.

Rahman M., Banik S., Faruque A.S.G., Taniguchi K., Sack D.A., Van Ranst M. and Azim T., Detection and characterization of human group C rotaviruses in Bangladesh, J. Clin. Microbiol. 43, $2005,4460-4465$.

Rodger S.M., Bishop R.F. and Holmes I.H., Detection of a rotavirus-like agent associated with diarrhea in an infant, J. Clin. Microbiol. 16, 1982, 724-726.

Saif L.J., Bohl E.H., Theil K.W., Cross R.F. and House J.A., Rotavirus-like, calicivirus-like, and 23-nm virus-like particles associated with diarrhea in young pigs, J. Clin. Microbiol. 12, 1980, 105-111.

Tamura K., Stecher G., Peterson D., Filipski A. and Kumar S., MEGA6: Amolecular evolutionary genetics analysis version 6.0, Mol. Biol. Evol. 30, 2013, 2725-2729.

Torres-Median A., Isolation of an atypical rotavirus causing diarrhea in neonatal ferrets, Lab. Anim. Sci. 37, 1987, 167-171.

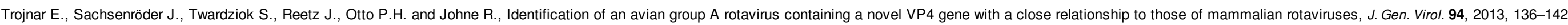

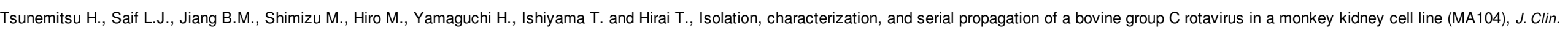

Microbiol. 29, 1991, 2609-2613.

Tsunemitsu H., Jiang B. and Saif L.J., Sequence comparison of the VP7 gene encoding the outer capsid glycoprotein among animal and human group C rotaviruses, Arch. Virol_ 141, 1996, 705-713.

\section{Appendix A. Supplementary data}

The following are the supplementary data to this article:

Multimedia Component 1

Multimedia Component 2

Multimedia Component 3

Multimedia Component 4 
Highlights

- Genetic diversity of porcine RVC strains.

- Novel genotypes of RVC VP4 and VP6 genes.

- Frequent reassortment events of RVC strains.

\section{Queries and Answers}

Query: Please confirm that given names and surnames have been identified correctly.

Answer: We have checked given names and surnames. It is correct!

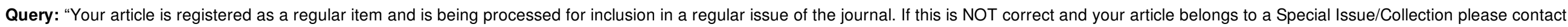
j.millard@elsevier.com immediately prior to returning your corrections.".

Answer: Our article is just a regular item.

Query: Please provide grant number, if any for 'Chonnam National University'.

Answer: It is not necessary to provide grant number for 'Chonnam National University'. Please keep it as it was!

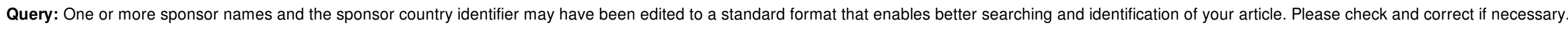

Answer: It is not necessary to correct sponsor names! Please keep it as it was! 